\title{
Le "Fantóme" de Lautréamont
}

En el último volumen de cuentos publicado por Julio Cortázar, Todos los fuegos el fuego," hay uno, "El otro cielo", que sintetiza en forma tal vez demasiado explícita, la visión del mundo y del arte que tiene el escritor argentino. Es una narración en primera persona, atribuida a un personaje que dice "yo" y que vive simultáneamente en Buenos Aires (entre 1928 y 1945) y en París (hacia 1868). En el cuento, los tiempos y los espacios son contiguos: el "yo" se mueve, dentro del mismo párrafo $\mathrm{y}$ a veces dentro de la misma frase, sin interrupción o aclaración alguna, de la Galería Güemes en el Buenos Aires de 1928 al barrio de las galerías cubiertas, cerca de la Bolsa de París, en 1868. El "yo" es simultáneamente un joven argentino, tímido ante el sexo y lleno de nostalgia por un mundo que no conoce (el otro cielo), y un argentino habitante de París que corre tras las prostitutas y está feliz de haber dejado en Buenos Aires aquel frustrado "yo". En una sola línea ininterrumpida, el narrador une los dos tiempos y los dos espacios, I entrelaza inextricablemente las diferentes y complementarias experiencias del mismo personaje. Porque hay un solo "yo", como lo ilustran tantos pasajes. Por ejemplo, éste:

Todavia hoy me cuesta cruzar el Pasaje Güemes sin enternecerme irónicamente con el recuerdo de la adolescencia al borde de la caída; la antigua fascinación perdura siempre, y por eso me gustaba echar a andar sin rumbo fijo, sabiendo que en cualquier momento entraría en la zona de las galerías cubiertas, donde cualquier sórdida botica polvorienta me atraía más que los escaparates tendidos a la insolencia en las calles abiertas. La Galerie Vivienne, por

1 Todos los fuegos el fuego fue publicado originariamente por Sudamericans (Buenos Aires, 1966). Cito por la presente edición. "El otro cielo" está en las PP. 167-97. 
ejemplo, o el Passage des Panoramas con sus ramificaciones, sus cortadas que rematan en una librería de viejo donde quizá nadie compre nunca un billete de ferrocarril, ese mundo que ha optado por un cielo más próximo, de vidrios sucios y estucos con figuras alegóricas que tienden las manos para ofrecer una guirnalda, esa Galerie Vivienne a un paso de la ignominia diuma de la rue Réaumur y de la Bolsa (yo trabajo en la Bolsa), cuánto de ese barrio ha sido mío desde siempre, desde mucho antes de sospecharlo ya era mio cuando apostado en un rincón del Pasaje Güemes, contando mis pocas monedas de estudiante, debatía el problema de gastarlas en un bar automático o comprar una novela y un surtido de caramelos ácidos en su bolsa de papel transparente, con un cigarrillo que me nublaba los ojos y en el fondo del bolsillo, donde los dedos lo rozaban a veces, el sobrecito del preservativo comprado con falsa desenvoltura en una farmacia atendida solamente por hombres, y que no tendría la menor oportunidad de utilizar con tan poco dinero y tanta infancia en la cara. (pp. 169-170).

En ese párrafo el "yo" parte del Pasaje Güemes (impregnado en la nostalgia de la adolescencia) y entra en la zona de las galerías cubiertas, en la Galerie Vivienne de París, para volver a regresar al Pasaje Güemes, sin otra transición que la establecida por un punto que divide el párrafo en dos mitades. Pero el punto no separa las dos zonas ya que antes y después del punto, la Galería Güemes abre paso a la Galerie Vivienne, o viceversa. La unidad aparece revelada por el uso sistemático de párrafos, como éste, que se mueven de Buenos Aires en este siglo al París del siglo pasado para volver a Buenos Aires, sin interrumpir la fluidez de la narración. La contigüidad de los espacios así como la simultaneidad de los tiempos quedan establecidas por el movimiento de cada párrafo, de cada frase, de cada miembro sintáctico.

Esa unidad sintáctica sirve, además, para subrayar la secreta unidad entre tiempos y espacios tan distintos como las paralelas pero opuestas experiencias del "yo" de Buenos Aires y el "yo" de París. Así, la narración también establece sutilmente un paralelo histórico que puede escapar a una lectura apresurada del cuento. En tanto que Buenos Aires, entre 1928 y 1945 , es progresivamente ocupada por su propio cjército hasta que con el ascenso de Perón a la Presidencia se consolida el completo control, París, en los años de 1860 y tantos vive bajo la amenaza de una invasión extranjera: los prusianos habrán de ocupar 
Francia en 1870. De la misma manera, aunque las experiencias del "yo" que vive en París y las del de Buenos Aires son distintas, las mismas tensiones y miedos las subrayan.

Para el adolescente de Buenos Aires, 1928, el sexo es una tentación a la que no se atreve a sucumbir: pasa y repasa por la Galería Güemes, mirando furtivamente los cines donde dan peliculas pornográficas, los puestos de revistas prohibidas, los anuncios de manicuras que encubren bajo esa especializada vocación los servicios de la más antigua profesión del mundo. Apretando el sobrecito que contiene el perservativo que (él sabe) nunca se atreverá a usar, el adolescente de Buenos Aires sufre las torturas de Tántalo. Para el joven que vive en Paris, en cambio, la zona de las galerías cubiertas es la zona de la libertad; allí encuentra las mujeres que le facilitan el placer, allí realiza los sueños masturbatorios del adolescente de la Galería Güemes. La oposición encubre, sin embargo, un paralelo mucho más complejo, como se verá.

Hay otra característica externa de esta narración que sirve para subrayar la unidad textual. Cada una de las dos secciones en que se divide el cuento se abre con un epígrafe en francés. El primero dice:

Ces yeux ne t'appartient pas... où les a tu pris?

$$
\ldots \ldots . . . . ., I^{\prime}, 5
$$

El segundo es un poco más largo:

Où sont-ils passés les becs de gaz? Que sont-elles devenues les vendeuses d'amour? $\ldots \ldots \ldots$, VI, 1

Aunque Cortázar muy explícitamente evita toda otra identificación de ambos epigrafes que esas cifras al pie de cada uno, en el texto del relato ofrece algunas indicaciones que sugieren la fuente literaria: Les Chants de Maldoror, largo poema narrativo que publica en París (precisamente en 1868), Isidore Ducasse bajo el seudónimo de Conde de Lautréamont.2

Una consulta al original permite advertir que en el primero de los

2 Cito por la edición de Osuvres Complètes, publicada por GLM, en Patis, 1938. Les Chants de Maldoror está en las pp. 1-294. 
dos epígrafes, el protagonista, Maldoror, enfrenta a un fantasma que visita su habitación, una sombra intrusa cuyos ojos lo hechizan. Maldoror lo apostrofa, reconoce en él a un símbolo del mal, admite ser su discípulo (aunque no pretende disputarle "la palme du mal") hasta que finalmente termina por descubrir el secreto del fantasma:

Ce qui me reste à faire, c'est de briser cette glace, en éclats, à l'aide d'une pierre... C'est ne pas la première fois que le cauchemar de la perte momentanée de la mémoire établit sa demeure dans mon imagination, quand, par les inflexibles lois de l'optique, il m'arrive d'être placé devant la méconnaissance de ma propre image! (p. 187).

Tenía razón Maldoror: esos ojos no eran del fantasma sino suyos.

El segundo epígrafe se refiere explícitamente al barrio de las galerías cubiertas, barrio en el que vivió Lautréamont/Ducasse los últimos meses de su corta vida (murió en 1870) y que era también el barrio que recorría Maldoror en sus delirios de la vigilia. Allí, y poco después de las dos frases que cita Cortázar en su epígrafe, Maldoror ve pasar el joven Mervyn, suette de doble byroniano de sí mismo, cuya figura llena las páginas del canto sexto. La noción de doble se enriquece y complica con este personaje. Pero lo que quisiera subrayar aquí no es esto, sino la presencia (en el texto de Lautréamont como en el de Cortázar) del espacio de las galerias como espacio privilegiado para la aparición de esos jóvenes solitarios y malditos, acicateados por el deseo, entregados a la sistemática persecución de otras sombras. Un vínculo sutil se establece así entre Maldoror/Mervyn por un lado, y el "yo" parisino del narrador de "El otto cielo".

Una observación complementaria. En una suerte de prefacio al canto sexto, y antes de entrar a describir el barrio de las galerias, Lautréamont define su propósito al escribir ese texto que él califica de novela (roman) (p. 250). Una de sus frases más notables merece citarse:

Les cinq premiers récits n'ont pas été inutiles; ils étaient le frontispice de mon ouvrage, le fondement de ma poétique future: et je devais à moi-même, avant de boucler ma valise et me mettre en marche pour les contrées de l'imagination, d'avertir les sincères amateurs de la littérature, par l'ébauche rapide d'une généralisation claire et précise, du but que j'avais résolu de poursuivre. En consequénce, mon opinion est que, maintenant, la partie synthé- 
tique de mon oeuvre est complète et suffisamment paraphrasée. C'est par elle que vous avez appris que je me suis proposé d'attaquer l'homme et Celui qui le créa. Pour le moment et pour plus tard, vous n'avez pas besoin d'en savoir davantage! (p. 251)

Queda aquí en evidencia el propósito blasfematorio de estos Canios, que vincula hondamente la hazaña de Lautréamont con la de otro gran rebelde, el Marqués de Sade, como se verá luego. Pero ahora me interesa más subrayar el sentido general de estos dos epígrafes en el contexto de la narración cortazariana. El primer epígrafe revela explícitamente el tema del doble: el fantasma que hechiza a Maldoror es una reflexión especular de sí mismo, de la misma manera que el "yo" parisino es un reflejo (en el espejo del otro cielo) del de Buenos Aires. El segundo epígrafe parece subrayar explícitamente otro tema: el deseo que arrastra a Maldoror a recorrer el barrio de las galerías cerradas tras la figuta de Mervyn, como arrastra al "yo" parisino a recorrerlas tras la figura de Josiane. Pero implícito dentro del tema del deseo está el tema del Otro, del doble, que el texto de Lautréamont revela tan nítidamente.

La unidad de las dos experiencias (la de Maldoror, la del doble protagonista del cuento) tesulta reforzada entonces por el diálogo secreto que se establece entre los dos epígrafes y el texto de Cortázar y que complementa el diálogo explícito. Les Chants de Maldoror permite subrayar de esta manera, la unidad textual del cuento al mismo tiempo que proporciona una clave para su análisis. ${ }^{3}$

\section{III}

El tema del doble puede ser encarado desde otros ángulos en la lectura de "El otro cielo". Porque hay otros dobles. Cuando el "yo". recorre las galerías en busca de Josiane, la prostituta de la que está enamorado, el barrio vive bajo el terror de un asesino de mujeres. Aunque menos minuciosamente sádico que Jack the Ripper, ese asesina (Laurent) no es menos eficaz: con sus grandes manos desnudas suele estrangular mu. jeres. Los encuentros del "yo" con Josiane se realizan sobre un fondo de terror y con el espasmo del miedo al asesino invisible pero omnipre-

3 Alejandra Pizarnik ha escrito un fino artículo sobre este mismo cuento. Alli examina algunas relaciones entre el texto de Lautrèamont y el de Cortázar pero llega a conclusiones diferentes a las de este trabajo. Su artículo está recogido en el volumen colectivo. La vuelta a Costázar en nueve ensayos (Buenos Aires: Carlos Pérez, 1968), pp. 55-62. 
sente, como incentivo perverso para esos episodios en el laberinto de las galerías. No es, sin embargo, Laurent el único individuo que acecha a las prostitutas.

Hay también un "sudamericano", muy alto y joven, delgado, silencioso, que el narrador contempla desde lejos, sin atteverse a abordar, aunque se siente tentado a hacerlo aunque más no sea por ser él también sudamericano. Aquel solitario tiene gustos perversos hasta el punto que una de las compañeras de Josiane, La Rousse, se niega a satisfacerlos a pesar de la notoria amplitud de miras de las prostitutas francesas en esta materia. (No se dice cuál sea la perversión; tiene algo que ver con una forma de voyeurismo, vinculada tal vez a la coprofilia, según se insinúa en la p. 181.) Por algún tiempo, las prostitutas sospechan que el "sudamericano" sea Laurent. Luego el verdadero Laurent es encontrado junto al cadáver de su última víctima: era un marsellés y no tenía nada que ver con el "sudamericano".

Pero la verdadera identidad de éste último es insinuada en el texto por medio de referencias aisladas: es joven, vive aislado, escribe mucho, muere solo en una piecita de hotel en el barrio de la Bolsa, poco antes de la victoria prusiana. No es difícil reconocer a Maldoror/Lautréa. mont/Ducasse en esta figura. De esta manera se refuerza el diálogo establecido por los epígrafes. Al convertir al autor de los Cantos en personaje no explícitamente identificado de "El otro cielo", Cortázar está aludiendo a la función de aquella obra en la concepción de su relato. Una detallada comparación del cuento (sobre todo en los pasajes que se refieren a la vida en el Paris de 1868) con el canto sexto de Lautréamont permitiría advertir hasta qué punto Cortázar utiliza el texto francés como fuente de muchos detalles concretos del suyo. Este examen es aqui imposible. Baste indicar que no se trata sólo de aislados préstamos estilísticos. Se trata de algo mucho más importante: la absotción de una atmósfera y de un lugar literario; la adopción de un sistema de visión; la incorporación del tema y de las obsesiones del mo. delo; el préstamo deliberado de una figura, de un "fantasma".

Porque no sólo el "sudamericano" es Lautréamont/Ducasse. Hay otras identidades más que el texto se encarga de insinuar o de marcar explícitamente. Empecemos por la que se establece entre Laurent y el "sudamericano". Al hablar de la muerte sucesiva de ambos, el narrador comenta:

...las dos muertes que de alguna manera se me antojaban simétricas, la del sudamericano y la de Laurent, el uno en su pieza de 
hotel, el otro disolviéndose en la nada para ceder su lugar a Paul el marsellés, y eran casi una misma muerte... (pp. 195-96).

Esa identidad simbólica de Paul Laurent y el "sudamericano", reflexión especular el primeto del segundo, queda además subrayada por otra circunstancia: la alusión a Lautréamont contenida en el nombre de Laurent que escoge Cortázar para el asesino. Es posible dividir ambos nombres para revelar mejor esa identidad simbólica: Lau-re-nt y Lau-tré-amo- $n$ t comparten las mismas letras subrayadas, y en la misma secuencia. Laurent es una reducción de Lautréamont -una parte de éste.

Ya se sabe que los dobles, o las imágenes especulares, tienden a reproducir sólo una parte, y en forma distorsionada, del ser que reflejan. En una de las más famosas novelas sobre este tema, The Strange Case of Dr. Jekyll and $\mathrm{Mr} H y d e$, de Stevenson, Hyde no sólo más joven y vigoroso que Jekyll; también es más pequeño $y$ brutal; es como una concentración, en el sentido del mal, del médico. En otra célebre historia de dobles, el relato "The Jolly Corner", de James, el otro yo del protagonista es una figura repugnante y oscura, con una cicatriz que le cruza la cara. De la misma manera, Laurent of rece una imagen distorsionada, en el espejo oscuro del crimen, de Lautréamont, el "montevideano", como le gustaba llamarse. Si el "sudamericano" de Cortázar es, como todo parece indicar, el "montevideano", entonces Laurent y el "sudamericano" aparecen no sólo unidos por sus muertes sino por esa identidad simbólica que se revela en la terminación de sus destinos. Sólo sus muertes (como en Stevenson) revelan la identidad.

La simultaneidad de las muertes de Laurent y el "sudamericano" también contribuye a llamar la atención, en forma indirecta, sobre una cierta comunidad en el mal que vincula a esos dos personajes, y que se transfiere naturalmente también al modelo, Lautréamont. Aunque es obvio que Maldoror/Lautréamont/Ducasse nunca cometieron ningún crimen "real", la creación de Les Chants de Maldoror, ese libro deliberadamente blasfemo y hasta satánico, como se ha visto, puede ser considerada como una transgresión que tiene las caractetísticas de un crimen. Hasta el nombre, del personaje central del libro puede ser descodificado como Mal d'arrore, el Mal naciente.

Para poder entender mejor ese nivel de significación del libro y del 
personaje es necesario remitirse a algunas interpretaciones que derivan, originariamente, de ciertos textos de Georges Bataille. Esa lectura de Bataille apunta a una concepción de la literatura como transgresión, de la escritura como blasfemia, del acto de escribir como un crimen. En uno de los más luminosos ensayos de Severo Sarduy, "Del Yin al Yang", se intenta la reconstrucción parcial de lo que podria ser el sistema de Bataille. No es casual que el ejercicio de Sarduy tenga como uno de sus temas precisamente un texto de Cortázar, en el que la huella del autor de Les Larmes d'Eros es más visible. Por eso me parece necesario detenerme un momento en el repaso del ensayo de Sarduy."

Su propósito explícito es seguir la trayectoria de una imagen, desde el libro citado de Bataille hasta Rayuela y Farabeuf, del mexicano Salvador Elizondo, pasando por la Storia di Vous, del italiano Marmori. Para este recuento es posible prescindir tanto de Marmori como de Elizondo. Lo que no es posible es prescindir del Marqués de Sade, con quien abre Sarduy su investigación. Lo primero que subraya Sarduy es que en su delirio textual, el Marqués busca una sola cosa: "Fijar, impedir el movimiento" (p. 11). Es decir: privar al Otro de su libertad, reducirlo al estado de objeto, atado, fijado; esto restituye al sádico "su total arbitrio, lo devuelve al estado inicial de posible absoluto, lo libera, lo "desata" ". (p. 11).

Es sabido que en la realidad, histórica, Sade casi nunca realizó su propósito. Hay alguna oscura historia de prostitutas, cantáridas, flagelación y sodomía, pero qué mediocre resulta todo esto frente a los excesos textuales de sus Obras completas. Donde Sade sí realizó su experiencia fue en el texto; su transgresión fue, sobre todo, literaria. Prosiguiendo su análisis, Sarduy muestra luego que el sadismo, como ideología, supone un espacio que es, primero, cristiano, y que al ser refutado pot Sade pasa a ser deista para terminar siendo gobernado por un Dios malvado (p. 13). Esa "refutación de la impostura divina se complace en su reiteración continua. (...) este rechazo, esa plegaria al revés, ese otro conjunto, tienen un valor erótico." (p. 13).

Me parece innecesario subrayar hasta qué punto esta interpretación de la blasfemia en Sade coincide con la posible interpretación de la blasfemia en Les Chants de Maldoror. Ya se ha visto que en el prefacio al canto sexto, Lautréamont indica muy explícitamente este aspecto de su obra. De la misma manera, lo que Sarduy dice sobre Bataille en su ensayo citado, también permite iluminar ciertas zonas de Maldoror. Para Bataille, en la síntesis de Sarduy, tres son las posibles transgresiones del

1 Escrito sobre un Euerpo (Buenos Aires: Sudamericana, 1969), pp. 9-30. 
pensamiento: el propio pensamiento, el erotismo y la muerte. Las tres transgresiones han sido castigadas por la sociedad burguesa en su origen, aunque de las tres, la que no perdona es, sobre todo, Ia primera: que el pensamiento se piense a sí mismo, que la lengua y la literatura se hablen a sí mismas.

Blasfemia, homosexualidad, incesto, sadismo, masoquismo y muerte son ya transgresiones relativamente toleradas. (No hablo de la transgresión pueril que es el arte "de denuncia" el pensamiento burgués no sólo no se molesta, sino que se satisface ante la represeritación de la burguesía como explotación, del capitalismo como podredumbre.) Lo único que la burguesía no soporta, lo que la "saca de quicio", es la idea de que el pensamiento pueda pensar sobre el pensamiento, de que el lenguaje pueda hablar del lenguaje, de que un autor no escriba sobre algo, sino escriba algo (como proponía Joyce). Frente a esta transgresión, que era para Bataille el sentido del despertar, se encuentran, repentina y definitivamente de acuerdo, creyentes y ateos, capitalistas y comunistas, aristócratas y proletarios, lectores de Mauriac y de Sartre.

(pp. 19-20).

La literatura como transgresión última del pensamiento; la literatura conro expresión de otras transgresiones (el erotismo, la muerte): tales serían las fórmulas en que vendrían a coincidir Sade y. Bataille con Lautréamont. Que también Cortázar puede sumarse a ese escogido grupo es lo que concluye de demostrar el ensayo de Sarduy al estudiar la relación que hay entre un episodio de Rayuelo y unas páginas de Les Larmes d'Eros. Me tefiero a las fotografías que ilustran la tortura china de los cien pedazos, o Leng-Tch'e, a las que hace referencia Wong en el capítulo 14 de la novela de Cortázar, y que son reproducidas parcialmente por Bataille en las pp. 232-234 de su libro citado..$^{5}$ En la lectura que hace Wong de esas fotografias, como en las interpretaciones de Bataille, están intimamente ligadas las tres transgresiones: el erotismo sádico y la muerte en la tortura misma; la transgresión literaria en los textos que ilustran o completan verbalmente las fotografías.

s Les Larmes d'Eros ha sido publicada por Jean-Jacques Pauvert (Paris, 1961). Rayuela, por Sudamericana (Buenos Aires, 1963), el capítulo 14 está en las pp. 70-72. En su última novela, Cobra (Buenos Aites: Sudamericana, 1972), Severo Sarduy también alude al Leng-Tch'e. Véase, especialmente, las pp. 114-115. Hay un artículo mío sobre esta novela, "Severo Sarduy: Las me. tamorfosis del texto". (publicado en Plural, México, 1973), ẹn que sẹ analiząn estas relaciones entre Bataille, Cortázar y Sarduy. 
Hasta aqui, Sarduy y las observaciones que su admirable ensayo suscita. Al volver al relato " $\mathrm{El}$ otro cielo", conviene observar que esa interpretación de la literatura como transgresión final permite advertir un lazo más que vincula al asesino Laurent con el "sudamericano". Es cierto que este personaje, como Lautréamont, es inocente de todo otro crimen que el de escribir pero lo que él escribe es una transgresión para la sociedad burguesa en que se inscribe su obra, una blasfemia, equivalente a la del erotismo o la muerte. Sú mismo voyeurismo es como un emblema de la otra transgresión: es culpable por querer ver más, por querer violar el tabú con la mirada, de la misma manera que su escritura viola también otros tabúes.

En las alusiones de "El otro cielo" a Les Chants de Maldoror hay otra forma de vincular al "sudamericano" con Laurent: ambos recorren el barrio de las galerias, acosados por el mismo impulso de ir más allá, de transgredir; ambos terminan por cometer actos (asesinar, escribir) que son formas de transgresión última contra la sociedad; ambos mueren igualmente condenados. De esta manera, Laurent se convierte en el doble, o fantasma, del "sudamericano". Pero hay más, como se verá.

\section{$\mathrm{V}$}

La pareja Lautréamont-Laurent implícita en la del "sudamericano" con Laurent, también artoja alguna luz sobre la pareja formada por el "yo" de Buenos Aires y el de París. La misma oposición sexual que se crea entre el voyetrr y el asesino (el impotente que mira, el que actúa) se encuentra entre las dos imágenes del narrador. El ritual que ejecuta el adolescente en la Galería Güemes de 1928, su búsqueda voyeurística de alguna satisfacción vicaria para sus frustrados deseos, contrasta en forma reiterada con el ritual que ejecuta el joven en el barrio parisino de las galerías. Este entra en el laberinto, elige a Josiane, sube con ella a la buhardilla, la posee, se siente sexualmente liberado. Cumple el acto sexual ("Ia petite morte", en que metaforizan los franceses el orgasmo) como Laurent cumple el acto criminal. Al usat sus enormes manos des. nudas para estrangular a sus víctimas, Laurent alcanza el orgasmo. Para él, el asesinato es una experiencia erótica. Ẽl realiza la "petite morte" en forma que no es enteramente metafórica. El paralelo entre Laurent y el "yo" parisino se hace visible por medio de este doble orgasmo y esta doble muerte.

De la misma manera, el "yo" de Buenos Aires y el "sudamericano" 
comparten semejantes tendencias voyeurísticas, la misma impotencia para satisfacer sus deseos. Aunque el argentino se casa al fin, resulta bastante claro que ese matrimonio no traerá la satisfacción de sus deseos. El seguirá anhelando el otro cielo de las galerías parisinas, la libertad que tiene su "yo" de 1868. Tendrá tanta envidia de él como el "sudamericano" podria tener de Laurent. Por eso, y de modo similar, en tanto que el "sudamericano" encuentra en la escritura, la transgresión literaria, un equivalente de los crímenes sexuales de Laurent, el "yo" de Buenos Aires encuentra en sus sueños sobre el "yo" de Patís una compensación para sus frustraciones.

Del mismo modo, si Laurent es el doble deformado en el espejo del "sudamericano", el "yo" parisino es la imagen deforme del de Buenod Aires: una imagen distorsionadamente feliz que se proyecta en la nostalgia de los sueños. Está enamorado de Josiane, encuentra el verdadero amor sexual en sus brazos, es libre. O lo parece. Porque hay otros fantasmas en este relato circular que termina por convertirse en un laberinto de ambiguas significaciones. El "yo" de Buenos Aires tiene un padrastro que no quiere que el muchacho fume tabaco rubio y que profetiza que acabará ciego si lo hace (p. 168). Esa prohibición y esa profecía parecen enmascarar otras, más comunes en el Buenos Aires de 1928: la vinculación del tabaco rubio con la mariconería; la de todo exceso sensual con la masturbación y con la decadencia física. Pero si el "yo" argentino tiene este padrastro, el de París no está libre de otra figura paterna, más o menos distorsionada. Josiane, naturalmente, es explotada por un "maquereau" que es su verdadero amo y amante. El amor que da Josiane al narrador está limitado y frustrado por la presencia ocasional de ese hombre. El podrá poseer a Josiane peto el Otro es su dueño.

La configuración edípica de todo el cuento se revela en esta doble parcja del padrastro y el "maquereau". Lo que esta pareja sugiere es que el "yo" parisino no está tan liberado como cree. Aún en el otro cielo de las galerías él debe aceptar la presencia, invisible pero dominante del Otro, el verdadero dueño. Por eso, lo que el "yo" realmente alcanza en París es sólo un simulacro de liberación: la limitada libertad sexual de un hombre que alquila una mujer por unas horas. Su amor por Josiane también tiene la configuración de un sueña masturbatorio.

El lo sabe. En un momento privilegiado de la narración cuando está a punto de hablar con el "sudamericano", y tiene cortedad y no lo hace, siente que hizo mal al no hablar, que "estuvo al borde de un acto que hubiera podido salvarme" (p. 181). Cuál es la salyación, es lo que no 
dice. Pero puede conjeturarse que no es la salvación por el amor homosexual, aunque las implicaciones homosexuales de la figura Lautréamont/ Maldoror/Ducasse son conocidas. Es posible adelantar otra explicación.

Si lo que realmente libera a Laurent no es el sexo sino el asesinato, entonces lo que libera al "sudamericano" no es el sexo tampoco (que le está vedado, en la forma perversa que él quiere practicarlo), sino la escritura. Esos "muchos papeles borroneados" que ve un día en su cuarto la prostituta Kiki (p. 181), esa "consola atestada de libros y papeles" que se describe al hablar de su muerte (p. 195), atestiguan su profesión de escritor. En ambos casos, la liberación llega a través de la transgresión final del crimen o la escritura. La configuración doblemente sádica que implica esta identificación entre el asesinato y la literatura -no hay que olvidar que el marqués de Sade escribia sus crímenes, como subraya. Bataille- facilita la tespuesta adecuada a ese problema de la salvación a que alude el "yo" de París. El también como el "sudamericano" terminará por tecontar (es decir: escribir) sus "crimenes".

\section{VI}

Hay otros importantes elementos en la configuración sádica de este cuento. Si Laurent utiliza sus grandes manos para estrangular a sus víctimas, ahogándolas con un movimiento que simboliza la masturbación, su gesto también implica la conversión de la víctima (siempre una mujer) en un objeto fijo, completamente inmovilizado para que el sádico pueda ejercer sobre él su libertad. El "sudamericano", al negarse a tener relaciones normales con las prostitutas y exigir una perversión que implica la mirada, está también revelando la configuración sádica: la mirada inmoviliza, fija al Otro, en su condición de objeto, lo reifica, para liberar así al sádico.

La misma configuración funciona en forma aún más clara en un episodio lateral del relato que se convierte, sin embargo, en emblema del cuento entero. Es la ejecución de un condenado a la que asisten Josiane con el narrador y sus amigos. La guillotina decapita a la víctima (apenas una mancha blanca en los brazos negros de los verdugos, lo que enfatiza el paralelo con las actividades estrangulatorias de Laurent) mientras Josiane sufre espasmos de terror, clava las uñas en el brazo de "yo" y tiene un sacudimiento que equivale a un orgasmo brutal. Otra vez lą muerte sádiç y lạ "pequeña muerte" aparecen indiso- 
lublemente unidas. Al convertir al condenado en un objeto de contemplación, al inmovilizarlo con la mirada, mientras ella practica la libertad y alcanza el éxtasis, Josiane está actuando como Laurent con sus víctimas, como el "sudamericano" quisiera actuar, con las prostitutas.

Hay otra alusión en la forma en que es ejecutado el hombre. La muerte por decapitación es una forma simbólica de la castración; la ceguera con que amenaza el padrastro de Buenos Aires es otra forma de castración. Entre una y otra imagen corre la narración entera, va y viene, se vuelve sobre sí misma, se enrosca sobre sus propios pasos, para llevar al lector a un desenlace irónico en que el "yo" de Buenos Aires acepta pasivamente todo: una mujer que no quiere (y que ni siquiera, probablemente, desea), un trabajo que odia, un país que se hunde rápidamente en el pantano de la dictadura militar. Es decir: acepta la Muette. Porque lo que lo mantenía vivo era la capacidad de salir a recorrer Buenos. Aires en un año cualquiera de este siglo y entrar en el barrio de las galerías del Patís de 1868. Lo que lo mantenía vivó era la posibilidad de soñar despierto con una existencia libre (o aparentemente libre) en el otro cielo de París. Pero al aceptar Buenos Aires, el "yo" pierde la capacidad de encontrar el camino de las galerías, deja de vivir en París, deja de soñar despierto. Su destino aparece ahora como la inversión exacta del que corresponde al prota. gonista de "The Jolly Corner". En tanto que el "yo" decide quedarse en Buenos Aires y olvida encontrar el pasaje que lo llevaba antes a París, el protagonista de James descubre en el monstruoso doble que lo enfrenta en Nueva York una confirmación de que tuvo razón al elegir Europa.

\section{VII}

Otros diálogos podrían establecerse entre el cuento de Cortázar y varios textos publicados antes por él, como el cuento "Las puertas del cielo" que recoge Bestiario (1950). En esta versión, más torpe, llena de fabricado color local, la que vive simultáneamente en dos mundos opuestos, aunque no en dos tiempos lejanos, es la protagonista, uná ex-prostituta. También se podría establecer un paralelo entre "El otro cielo" y ese cuento, "Las babas del Diablo" que Antonioni y Tonino Guerra convirtieron en Blow-up (1967): la misma sádica configuración del fotógrafo voyeur, la misma insinuación de amor homosexual (más explícitạ eṇ la segunda nạrạción), la misma concepción del arte como 
forma de salvación, como una redención del Mal. El pasaje de una a otra ciudad, de Buenos Aires a París, está presentado en forma mucho más elaborada en Rayuela (1963), novela en la que ese pasaje aparece pautado por la múltiple presencia de dobles y por la misma configuración sádico-edípica. También aparece allí un emblema del asesinato ritual. En vez de la guillotina se encuentra en la novela una descripción detallada de la tortura china de los cien pedazos que deriva de Les Larmes d'Eros, como se ha visto.

Una comparación con 62. Modelo para armar (1968), sería de tigor porque esta novela utiliza, como el cuento, el pasaje de tiempos y espacios, la comunicación imaginaria de ciudades distintas que componen al cabo una ciudad, el tránsito especular de destinos. También en esta novela, Cortázar desarrolla aún más la vinculación ritual entre el sexo y el crimen, en la variante lesbiana esta vez. Finalmente, la exploración de algunos episodios de Los premios (1961) y del uso en esta novela del símbolo de la popa como el centro inaccesible, y tabú, de ese laberinto que es el barco, permitiría descubrir el mismo tema implícito de la salvación a través del arte o del amor homosexual.

Pero hay otro diálogo, no menos importante, que sí conviene señalar, y que también ocurre en la superficie del cuento, "El otro cielo": es el que se establece entre la persona triple de Isidore Ducasse/Lautréamont/Maldoror, y la del escritor Julio Cortázar. Al convertir a Ducasse, el "rtontevideano", en el "sudamericano" de su cuento, Cortázar no sólo está expandiendo voluntariamente hasta el continente entero el limitado ámbito topográfico del modelo: está subsumiendo la específica nacionalidad de Ducasse en otra, más general, que lo abarca a él también. De esa manera, Lautréamont se convierte en su antepasado.

Una última pareja queda en evidencia gracias a esta operación geográfica: Isidore Ducasse se convierte en el doble, especularmente invertido, de Cortázar. En tanto que aquél nació en Montevideo (1846), de padres franceses, Cortázar nació en Bruselas (1941) de padres argentinos. Ducasse fue educado en Francia y se convirtió en escritor francés, en tanto que Cortázar fue educado en Buenos Aires y se convirtió en escritor argentino. El aqui y alli tienen significaciones simétricamente opuestas para Lautréamont y Cortázar, como la izquierda y la derecha en las imágenes especularmente opuestas. Para Ducasse, que escribe en francés para un público francés, París es siempre aqui, y la región rioplatense en que nació es siempre alli; para Cortázar, que escribe en español y para un público hispánico, Buenos Aires es aqui y las orillas del Sena son alli. Si se desçodifica èl seudónimo de Lautréamont como 
L'autre monde (el otro mundo $=$ el otro cielo), el seudónimo apunta a América del Sur, el otro mundo del que viene el "montevideano", en tanto que para Cortázar como escritor, América Latina es su mundo, el aqui eterno de su literatura. (Que Cortázar esté radicado en Francia desde hace más de veinte años, que se haya hecho ciudadano francés últimamente, son accidentes de su biografia, no de su escritura.)

Estas configuraciones simbólicas, esta simetría especular, no ha impedido sin embargo que Cortázar haya intentado una identificación final con Lautréamont. Al contrario, ellas se acentúan por las mismas diferencias y ayudan a proyectar al escritor dentro del "yo" que narra "El otro cielo", ese personaje que casi habla con el "sudamericano" en el texto de 1868. En el diálogo que el texto del cuento establece con el texto de Les Chants de Maldoror el "casi" es redimido del mundo de posibilidades irrealizadas y el "yo" se encuentra con el poeta, Cortázar finalmente se enfrenta con el fantasma de Lautréamont.

EMIR RODRíguez-MONEGAL

Yale University. 
